\title{
NITROGEN CLEARANCE RATES OF RIGHT AND LEFT LUNGS IN DIFFERENT POSITIONS $* \dagger \ddagger$
}

\author{
By GLEN A. LILLINGTON,§ WARD S. FOWLER, R. DREW MILLER AND \\ H. FREDERIC HELMHOLZ, JR. \\ (From the Mayo Clinic and Mayo Foundation,\| Rochester, Minn.)
}

(Submitted for publication December 24, 1958; accepted July 23, 1959)

Uniform alveolar ventilation implies that during inspiration all alveoli simultaneously receive gas of the same chemical composition and of the same volume (relative to the previous preinspiratory volume) and that this mixes almost instantaneously with the preinspiratory alveolar gas. Studies with single or multiple inhalations of "reference" gases have shown that alveolar ventilation is nonuniform (uneven) in most normal men (2). The two principal theoretic explanations for this observation have been $a$ ) that inspired gases are stratified in the peripheral alveolar spaces or $b$ ) that different regions (central versus peripheral spaces of a lobe or segment; different lungs, lobes or segments) are ventilated at different rates. Although Roos, Dahlstrom and Murphy (3) again proposed the stratification theory, it was noted by Forster (4) that some of their experimental results could be equally consistent with a regional explanation.

The elimination rate (clearance) of pulmonary nitrogen $\left(\mathrm{N}_{2}\right)$ from the total lungs during inhalation of oxygen was found by Lundin (5) and by Svanberg (6) to be retarded in persons in the lateral decubitus position as compared with the rate in supine persons. The clearance curves of helium from the total lungs failed to demonstrate that alveolar ventilation was less uniform in the lateral decubitus than in the supine position (7). The present study was undertaken, in part, to

* A portion of this material is included in the thesis submitted by Dr. Lillington to the Faculty of the Graduate School of the University of Minnesota in partial fulfillment of the requirements for the degree of Master of Science in Medicine.

$\dagger$ This investigation was supported in part by Research Grant No. H-3588 from the National Heart Institute, Public Health Service, Bethesda, Md.

$\ddagger$ A preliminary report has appeared (1).

$\S$ Fellow in Medicine, Mayo Foundation.

\|The Mayo Foundation, Rochester, Minnesota, is a part of the Graduate School of the University of Minnesota. determine whether analysis of $\mathrm{N}_{2}$ clearance curves from the total lungs would clarify the nature of the retarded elimination of $\mathrm{N}_{2}$ seen in the lateral decubitus position. Such studies on a few normal persons were sufficient to confirm the results of Lundin (5) and of Svanberg (6), and to indicate further that the retardation of complete elimination of $\mathrm{N}_{2}$ was caused by both a reduction of alveolar dilution per breath and an increased degree of uneven ventilation.

In the lateral decubitus position, differences between the superior and the inferior lung in the clearance rates of alveolar gases were first shown directly in dogs (8) and later were shown (6) and calculated (9) to exist in man. In the present study, partial anatomic localization and further analysis of the uneven ventilation were obtained by measuring $\mathrm{N}_{2}$ clearance curves and the respiratory dead space of individual lungs during bronchospirometry with the subjects in several positions. The results, which are in essential agreement with those reported by Svanberg (10), indicate that uneven ventilation exists within and between lungs, and that the latter difference is subject to postural variations.

Several theoretic but unrecognized alterations that have arisen in Lundin's modification $(5,10$, 11) of the original method for analysis of pulmonary clearance curves reported by Fowler, Cornish and Kety (12) also will be indicated.

\section{PROCEDURES AND METHODS}

Studies on total lungs. The subjects were five normal men 30 to 40 years of age, with an average height of 183 cm. (175 to $193 \mathrm{~cm}$.) and weight of $82 \mathrm{Kg}$. (68 to $95 \mathrm{Kg}$.). After resting supine for 10 or more minutes, they breathed 99.5 per cent oxygen, using an open circuit, mouthpiece and nose clip, until the maximal $\mathrm{N}_{2}$ concentration of endtidal gas, as recorded continuously throughout each breath, was reduced to about 2 per cent. The expired volume was measured with a $120 \mathrm{~L}$. spirometer. This was done with the subjects in the supine and the right and left lateral 
decubitus positions in varying orders. For three of the subjects, duplicate measurements in each position were made, and the concentration of expired $\mathrm{N}_{2}$ and the expiratory flow also were recorded continuously, as noted below.

Studies on individual lungs. The subjects were five healthy male physicians 27 to 44 years of age and 179 $\mathrm{cm}$. in average height. Premedication and introduction of a Carlens bronchospirometric catheter were done as outlined by Wright and Michelson (13), and the proper location of the catheter was confirmed by fluoroscopy. The subject first assumed the left lateral (three subjects) or the right lateral decubitus position, with one pillow supporting the head; subsequently, he assumed the supine and then the other lateral decubitus position. The leak-free placement of the Carlens catheter was tested before and usually after each change of position. The lungs were connected to the four-way valves of an oxygen-filled, double, closed circuit spirometer (GaenslerCollins) via tubing and a two-channel rotary valve containing the sampling needle of a $\mathrm{N}_{2}$ meter that was used to analyze gases passing to and from one lung. The closed circuits were modified with large bore, threeway stopcocks and valves so that, while room air was being breathed, each circuit could be converted to an oxygen-filled open circuit for later measurement of the pulmonary $\mathrm{N}_{2}$ clearance rate. Gases expired from either lung on an open or closed circuit could be passed through a heated pneumotachograph similar to that of Lilly (14), a differential transformer-amplifier system being used as the transducer. In the initial lateral position and thereafter during changes of position, double closed circuit recordings were made to measure tidal volume and changes of the functional residual capacity. In the two lateral positions, $\mathrm{N}_{2}$ clearance rates were measured for the dependent and the superior lung in turn. In the intervening supine position, the $\mathrm{N}_{2}$ clearance rate was measured first on the previously dependent lung and then on the previously superior lung. Prior to any measurement of $\mathrm{N}_{2}$ clearance, both lungs breathed room air until the end-tidal $\mathrm{N}_{2}$ concentration was about 80 per cent; during each measurement of $\mathrm{N}_{2}$ clearance, the opposite lung continued to breathe room air.

Continuous recordings of $\mathrm{N}_{2}$ concentration and of expiratory flow were made with oscillographic galvanometers and a photokymograph at a paper speed of $25 \mathrm{~mm}$. per second. The Lilly type of $\mathrm{N}_{2}$ meter was calibrated for each subject with five known gas mixtures saturated at $37^{\circ} \mathrm{C}$. It provided an accuracy of about \pm 2 per cent $\mathrm{N}_{2}$ at high concentrations, \pm 1 per cent $\mathrm{N}_{2}$ at concentrations from 10 to 30 per cent and \pm 0.5 per cent $\mathrm{N}_{2}$ at lower concentrations. In the studies on total lungs, the $\mathrm{N}_{2}$ concentration of tidal gases was measured at the mouthpiece. With bronchospirometry, the sampling needle of the $\mathrm{N}_{2}$ meter was located so that tubing dead spaces of 12 and $31 \mathrm{ml}$. existed between it and the Carlens catheter and the four-way valve, respectively. The mean $\mathrm{N}_{2}$ concentration of gases expired during breathing of $\mathrm{O}_{2}$ as "seen" by the $\mathrm{N}_{2}$ meter was, therefore, greater than the true value, depending on the size of the tidal volume.
The appropriate correction, averaging 14 per cent, was applied to values for lung volume calculated from mean expired concentrations and mean tidal volume. A measured correction of 0.1 second was applied to account for lag of the $\mathrm{N}_{2}$ meter behind the simultaneous flowmeter recordings. Calibration of the flowmeter, from which the volumes pertaining to $\mathrm{N}_{2}$ clearance curves during bronchospirometry were derived, was made for each subject from the area of flowmeter recordings of two or more expirations, obtained with simultaneous measurements of volume by the spirometer.

Pulmonary $\mathrm{N}_{2}$ clearance rates were determined by the method of Fowler, Cornish and Kety (12). One modification was made in estimating the fractional concentration $\left(F_{b}\right)$ of the $N_{2}$ in expired gas that was eliminated from the blood during bronchospirometry. This was necessary because $\mathrm{N}_{2}$ was eliminated from the blood traversing the one lung that breathed $\mathrm{O}_{2}$ but was added to the blood traversing the other lung that breathed air. If it is assumed that half the cardiac output $(\dot{Q})$ traverses each lung and that the alveolar $\mathrm{pN}_{2}$ of the " $\mathrm{O}_{2}$ lung" is initially reduced abruptly to near zero, this lung initially will eliminate $\mathrm{N}_{2}$ from the blood at a maximal rate equal to $0.5\left(Q \times C_{\bar{v}}\right)$, where $C_{\bar{v}}$ equals the $\mathrm{N}_{2}$ concentration in mixed venous blood when the body is in $\mathrm{N}_{2}$ equilibrium with atmospheric air. Thereafter, the rate of elimination of $\mathrm{N}_{2}$ by this lung will decrease to a minimal constant value of $0.25\left(Q \times C_{\bar{v}}\right)$, which occurs when the mixed venous concentration equals $0.5 \mathrm{C}_{\bar{v}}$. This equilibrium is reached when the rate of uptake of $\mathrm{N}_{2}$ by the "air lung" equals the rate of elimination by the " $\mathrm{O}_{2}$ lung." The amount (milliliters) of $\mathrm{N}_{2}$ eliminated when both lungs breathe $\mathrm{O}_{2}$ for seven minutes, called here the "Cournand factor" (15), approximately equals $0.5\left(\dot{Q} \times \mathrm{C}_{\bar{v}}\right) \times 7$ minutes. Therefore, the correction factor used here, assuming the minimal constant elimination rate for the " $\mathrm{O}_{2}$ lung" was $F_{b}$, equals 0.5 Cournand factor divided by the number of breaths in seven minutes $\times V_{T}$, where $V_{T}$ is tidal volume. This correction is appropriate for the later parts of the pulmonary $\mathrm{N}_{2}$ clearance, when alveolar $\mathrm{N}_{2}$ concentrations are small; it will cause only negligible error in the early parts, when alveolar $\mathrm{N}_{2}$ concentrations are large.

In several instances, progressive changes in tidal volume occurring during $\mathrm{N}_{2}$ clearance precluded an accurate analysis of the total clearance curve. In these instances, the functional residual capacity was measured by summating the amounts (milliliters) of $\mathrm{N}_{2}$ eliminated on successive individual expirations (corrected for the $\mathrm{N}_{2}$ of blood and inspired gas) until the expired alveolar concentration was 5 per cent or less and dividing by the change of alveolar concentration, as by the method of Darling, Cournand and Richards (16).

The respiratory dead space for each lung was recorded as the average of measurements on two or more expirations, obtained from simultaneous records of $\mathrm{N}_{2}$ concentration and flow, using the "estimation" method of Fowler (17). The subcarinal dead space was obtained by substracting 22 and $29 \mathrm{ml}$. from the measured values for 


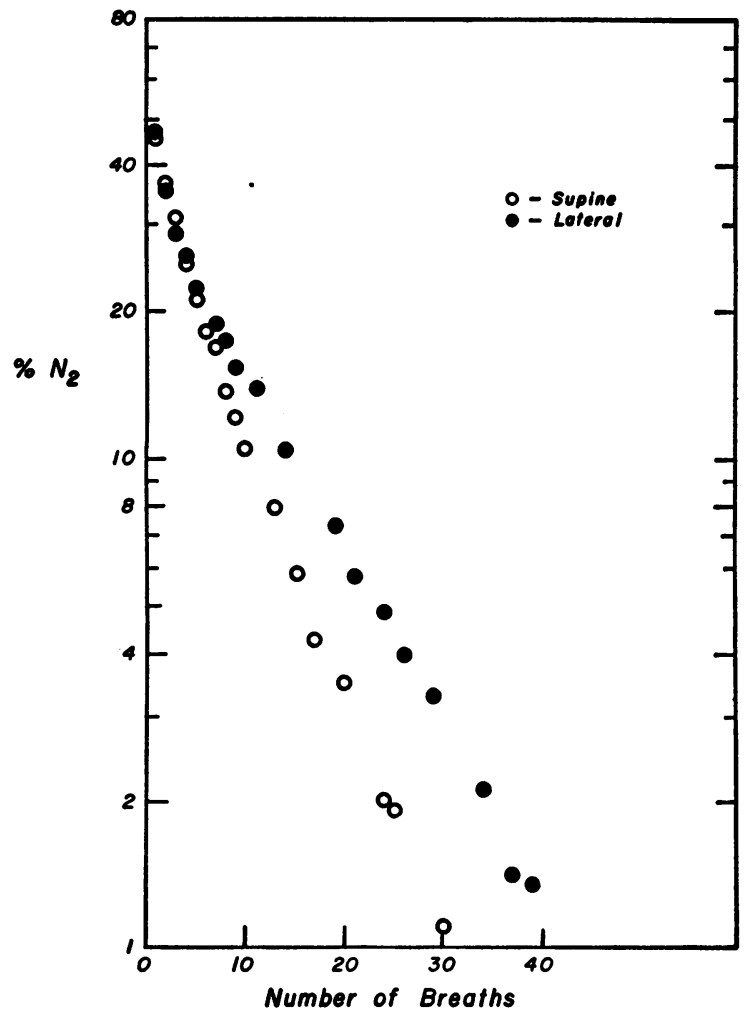

Fig. 1. Mean Concentration of Expired $\mathrm{N}_{2}$ During Clearance from Both Lungs

In the supine and right lateral decubitus positions, respectively, tidal volume was 550 and $537 \mathrm{ml}$., and functional residual capacity was 2,170 and $2,700 \mathrm{ml}$.

right and left lungs, respectively. These corrections represented the actual volume of channels of tubing and catheter $(27 \mathrm{ml}$. on the left and $24 \mathrm{ml}$. on the right), with a $5 \mathrm{ml}$. adjustment estimated to account for the asymmetric location of the catheter in the carinal region. The total dead space, as used in certain calculations, was the measured value plus $31 \mathrm{ml}$. of distal tubing.

\section{RESULTS}

\section{Total lungs}

Typical clearance curves are illustrated in Figure 1 and the results of their analysis are given in Table I. The tidal volumes in Table I were measured spirometrically, but the values for functional residual capacity and dead space were obtained by analysis of clearance curves. All clearance curves, plotted semilogarithmically, were nonlinear, but they could be resolved into two or three components, representing fractions of the functional residual capacity having different clear- ance or replacement rates. ${ }^{1}$ When the subject was supine, the more slowly ventilated component comprised about 80 to 90 per cent of the functional residual capacity; its fractional replacement per breath was about 10 per cent. For the total lungs, molecules of $\mathrm{N}_{2}$ remained for an average of about eight breaths, which was 24 per cent longer (delay in pulmonary clearance) than if alveolar ventilation had been uniform. The concentration of $\mathrm{N}_{2}$ in end-tidal gas was reduced to 5 per cent and 2 per cent in 1.8 and 2.8 minutes, respectively.

Results for the two lateral positions were combined, since consistent differences were not apparent. Here, the complete clearance was less rapid than it was in the supine position, as shown by significantly different mean values for both the time and the volumes required to reduce the endtidal concentration of $\mathrm{N}_{2}$ to 5 and 2 per cent, and by values derived from analysis of the clearance curves (Table I). These values indicated that the slower clearance was the result of $a$ ) reduction of

1 The method used for analysis of $\mathrm{N}_{2}$ clearance curves (12) is based on equations for a cyclically ventilated system of one or more bellows, within each of which ventilation is uniform, and from which the separate expired tidal volumes are combined. The $\mathrm{N}_{2}$ concentration within any one bellows will be reduced on each successive breath of $\mathrm{O}_{2}$ to a fraction of its preceding value, designated as $\mathrm{w}$, the alveolar dilution factor, when

$$
\mathrm{w}=\mathrm{V}_{\mathbf{L}} \div \mathrm{V}_{\mathrm{L}}+\left(\mathrm{V}_{\mathrm{T}}-\mathrm{V}_{\mathbf{D}}\right) \text { and }
$$

where $V_{L}$ is the volume in which $\mathrm{N}_{2}$ is contained at the end of expiration, $V_{T}$ is the tidal volume and $V_{D}$ is the volume of the dead space. The fractional replacement per breath equals 1-w. If there are two or more bellows or regions having different clearance rates, their alveolar dilution factors are $w_{1}, w_{2}$ and so forth, and $f_{1}$ and $f_{2}$ denote their respective decimal fractions of the total endexpiratory volume. Experimentally, the mean expired $\mathrm{N}_{2}$ concentration of successive breaths is measured and the semilogarithmic plot (Figure 1) is resolved graphically into one or more components. From the slopes and intercepts of the components, values of $w$ and $f$ are obtained; from these values, one can calculate the average interval during which molecules of $\mathrm{N}_{2}$ remained in the total system (actual average number of breaths), thus characterizing the clearance rate of the total system, and also the average interval during which molecules of $\mathrm{N}_{2}$ would remain in a uniformly ventilated system having the same total tidal volume, dead space and functional residual capacity as the components (ideal average number of breaths). A delay in pulmonary clearance indicates the extent to which complete clearance of $\mathrm{N}_{2}$ is retarded by the presence of uneven ventilation, that is, different replacement rates of various regions. 
TABLE I

Pulmonary $\mathrm{N}_{2}$ clearance of total lungs in supine and lateral decubitus positions*

\begin{tabular}{|c|c|c|c|c|c|}
\hline \multirow[b]{2}{*}{ Rowt } & \multirow[b]{2}{*}{ Factor } & \multicolumn{2}{|l|}{ Supine } & \multicolumn{2}{|c|}{ Lateral decubitus } \\
\hline & & Value & No. & Value & No. \\
\hline 1 & End-tidal $\mathrm{F}_{\mathrm{N}_{2}}$ to $0.05 \ddagger \min$. & $1.83 \pm 0.16$ & $\begin{array}{l}8 \\
8\end{array}$ & $2.86 \pm 0.16$ & 15 \\
\hline 2 & End-tidal $\mathrm{F}_{\mathrm{N}_{2}}$ to $0.02 \ddagger$ min. & $2.79 \pm 0.23$ & 8 & $4.12 \pm 0.22$ & 15 \\
\hline 3 & Tidal volume, $m l . \quad L$. & $\begin{array}{l}19.7 \pm 1.6 \\
625 \pm 65\end{array}$ & $\begin{array}{l}8 \\
8\end{array}$ & $\begin{aligned} 27.3 & \pm 1.6 \\
602 & \pm 46\end{aligned}$ & $\begin{array}{l}15 \\
15\end{array}$ \\
\hline 4 & Functional residual capacity (F.R.C.), $m l$. & $2,160 \pm 246$ & 6 & $2,950 \pm 274$ & 11 \\
\hline 5 & Dead space, $m l$. & $170 \pm 18$ & 6 & $155 \pm 11$ & 11 \\
\hline $\begin{array}{l}6 \\
7\end{array}$ & $\begin{array}{l}\text { Respirations per min. } \\
\text { Fractional replacement per breath }\left(1-\mathrm{w}_{2}\right)\end{array}$ & $12.2 \pm 1.1$ & 8 & $11.8 \pm 0.7$ & $1 \overline{5}$ \\
\hline & of rapidly ventilated component & $0.40 \pm 0.034$ & 6 & $0.34 \pm 0.028$ & 9 \\
\hline 8 & $\begin{array}{l}\text { Fractional replacement per breath }\left(1-w_{1}\right) \\
\text { of slowly ventilated component } \ddagger\end{array}$ & $0.114 \pm 0.005$ & 6 & $0.069 \pm 0.03$ & 11 \\
\hline 9 & $\begin{array}{l}\text { Slowly ventilated component fraction }\left(f_{1}\right) \\
\text { of F.R.C. }\end{array}$ & $86.3 \pm 2.8$ & 6 & $86.1 \pm 1.9$ & 11 \\
\hline 10 & Actual average number of breaths $\ddagger$ & $8.13 \pm 0.29$ & 6 & $13.4 \pm 0.62$ & 11 \\
\hline 11 & Ideal average number of breaths & $6.62 \pm 0.32$ & 6 & $9.15 \pm 0.41$ & 11 \\
\hline 12 & Pulmonary clearance delay, $\% \ddagger$ & $24 \pm 4.1$ & 6 & $47 \pm 4.1$ & 11 \\
\hline
\end{tabular}

* Volumes are BTPS (body temperature, ambient pressure, saturated). Values are mean \pm standard error of mean. No. is number of observations.

$\dagger$ Definition of Rows 7 through 12 are given in text Footnote 1.

$\ddagger$ Mean values differ significantly. Interindividual variation in functional residual capacity produces nonsignificant difference in the group mean, but all lateral values exceed supine values for the same subject.

$\S$ Two of the lateral decubitus curves contained a small third component $\left(w_{3}\right)$.

fractional replacement per breath for both the more slowly ventilated component (smaller value of $1-\mathrm{w}_{1}$ ) and for the total lungs (larger ideal average number of breaths), the latter being caused by an increase of functional residual capacity without a corresponding increase of ef- fective tidal volume, and $b$ ) an increase in the nonuniformity of ventilation (increased delay in pulmonary clearance).

Despite the considerable increase of end-inspiratory lung volume in the lateral positions, a significant change in the dead space was not ob-
LEFT LUNG

SUPINE

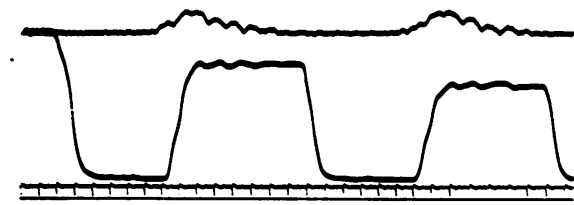

RIGHT

LATERAL

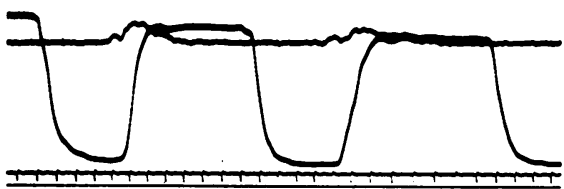

LEFT

LATERAL

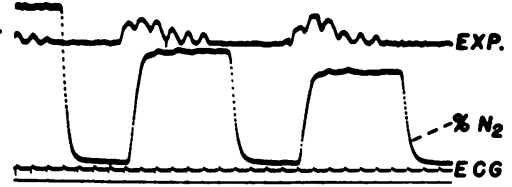

RIGHT LUNG
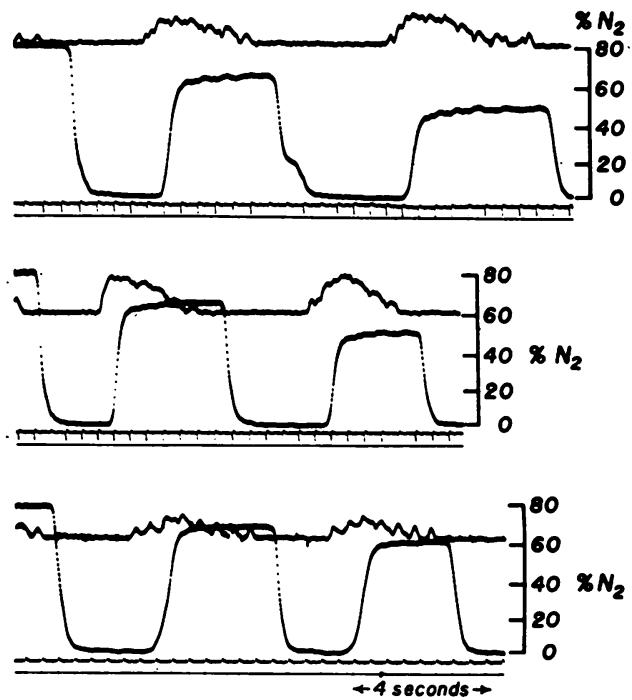

Fig. 2. Concentration of $\mathrm{N}_{2}$ and Expiratory Flow of Individual Lungs During First Two Breaths of Oxygen by One Subject

Records read from left to right. See text. 

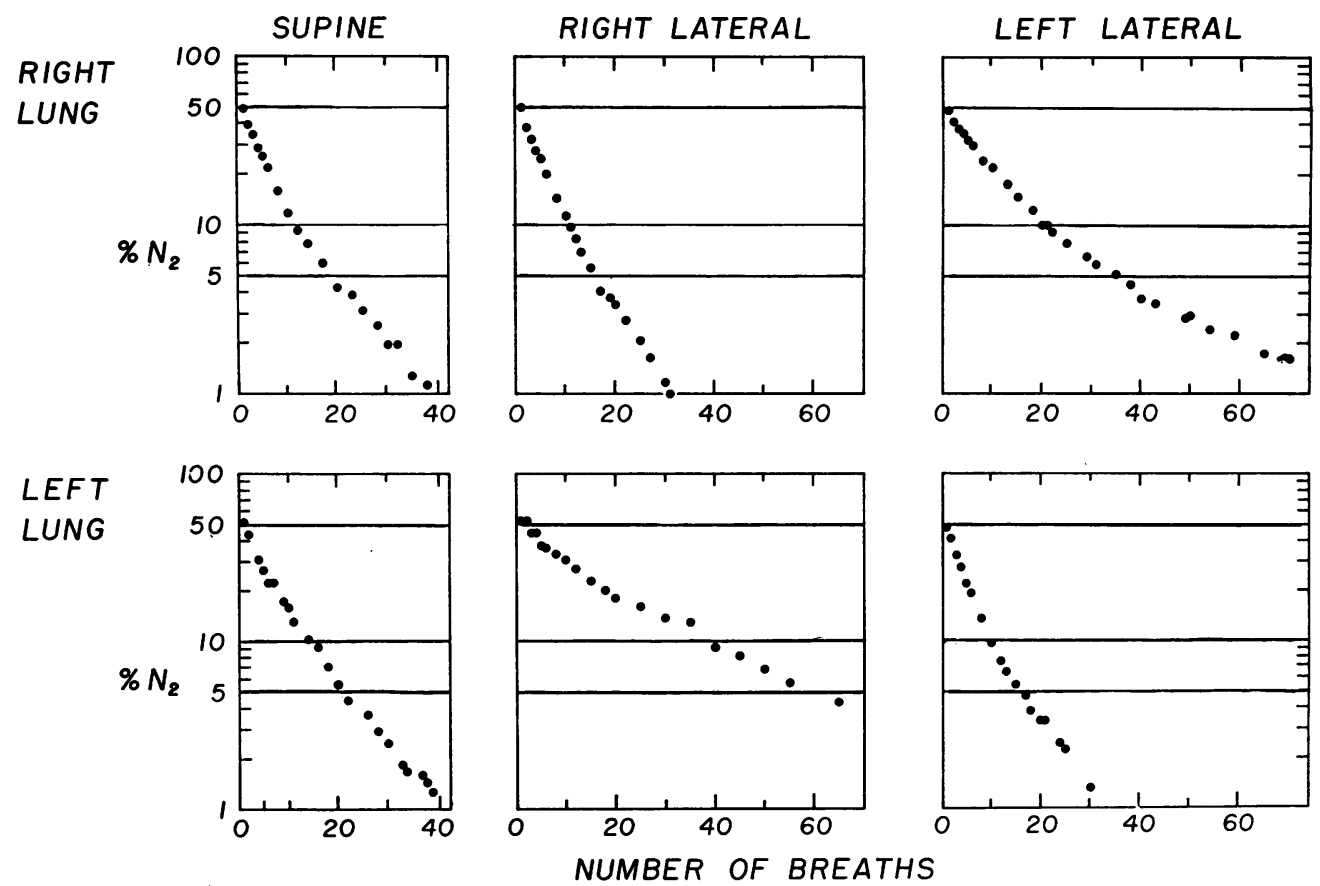

Fig. 3. Mean Concentration of Expired $\mathrm{N}_{2}$ During Clearance from Individual Lungs of One Subject in Different Positions

served. However, calculation of the dead space from clearance curves is of limited accuracy (12). Simultaneous records of the concentration of expired $\mathrm{N}_{2}$ and flow, needed for measurement of dead space on individual breaths (17), were available for three subjects. However, this method requires that expired alveolar gas be identifiable as a "plateau" of concentration, as is illustrated in the records from individual lungs (Figure 2). Suitable "plateaus" were observed in the supine position without bronchospirometry, but not in the lateral positions. After the initial increase in the concentration of $\mathrm{N}_{2}$ early in expiration, large and irregular variations of concentration, both increases and decreases, were frequently observed during the later part of expiration, precluding the identification of a plateau. This presumably resulted from a variable asynchrony of emptying of the two lungs. Further study of this phenomenon and of the dead space in the lateral positions is needed.

\section{Individual lungs}

Figure 2 shows typical recordings of the first two expirations while the subject breathed oxygen in various positions. In each expiration, the "alveolar plateau" showed a progressive variation in $\mathrm{N}_{2}$ concentration, qualitatively indicating uneven alveolar distribution of inspired $\mathrm{O}_{2}$. Also noted were variations in alveolar $\mathrm{N}_{2}$ concentration and expiratory flow occurring periodically at cardiac frequency (18); these will not be considered further in this report. The rate of decrease on successive breaths of the concentration of expired alveolar $\mathrm{N}_{2}$ was similar for both lungs in the supine position, but the rate in the lateral positions was less for the superior lung. Figure 3 presents typical corrected curves of the mean concentration of expired $\mathrm{N}_{2}$ vs. the number of breaths. These curves were in all cases nonlinear, indicating the presence of nonuniform alveolar ventilation, and they could be resolved into two components. The slower rate of clearance of $\mathrm{N}_{2}$ from the superior lung is evident.

Table II presents mean values derived from analysis of the clearance curves and also values of the respiratory dead space measured on individual breaths by the "estimation method" (17).

Supine position. The volume of the right lung was larger than that of the left, averaging 57 per cent of the total functional residual capacity. The right lung contained about 62 per cent of the total 
subcarinal dead space. However, the greater tidal volume of the right lung, about 55 per cent of the total, and its distribution were such that the average clearance rates of the two lungs were similar, as were the clearance rates of the rapidly and the slowly ventilated components. The latter comprised about 80 per cent of the functional residual capacity of each lung. The average interval during which molecules of $\mathrm{N}_{2}$ remained in the lungs was about one minute, corresponding to about 10 breaths, or a 10 per cent replacement of alveolar gas per breath. This was about 30 per cent less rapid than it would have been if alveolar ventilation had been uniform.

Lateral positions. When the subjects changed from the supine position to either of the lateral decubitus positions, the functional residual capacity of the dependent lung changed relatively little, whereas that of the superior lung increased by more than $0.5 \mathrm{~L}$. over its supine value. The average increase recorded by closed circuit spirometry was $680 \mathrm{ml}$. Consistent changes in the dead space of either lung were not observed.

When the subject was in a lateral decubitus position, the dependent lung uniformly received a greater percentage of both total and effective tidal volume than did the same lung when the subject was supine. ${ }^{2}$ The clearance rate of the right lung was slightly more rapid when dependent than when supine, as indicated by smaller values of the actual average number of breaths in four subjects and by a more rapid reduction of the end-tidal $\mathrm{N}_{2}$ concentration in a fifth subject, whose clearance curves were not all suitable for graphic analysis. More rapid clearance was achieved by small increases in the fractional replacement per breath and in the respiratory frequency (about one breath per minute).

The clearance rate of the left lung was not con-

\footnotetext{
2 The measurements in Table II were not obtained simultaneously on the two lungs. Simultaneous measurement by spirometry showed the percentage of total tidal volume received by the right lung to average 54,43 and 64 per cent for the supine, left lateral and right lateral positions, respectively, which corresponds with the consecutively measured tidal volumes in Table II. The percentage of effective tidal volume of the dependent lung increased when it was calculated from the total dead space of each lung and tidal volumes recorded either simultaneously or as in Table II.
}

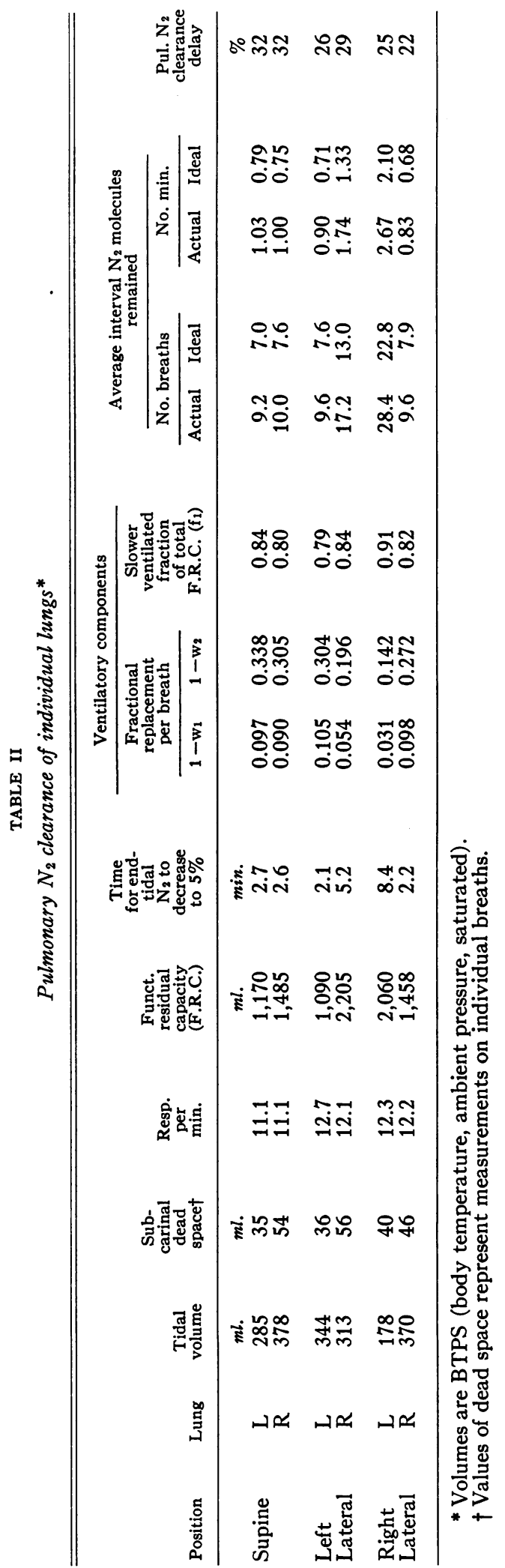


sistently different when it was supine and when it was dependent.

The clearance rate in superior lungs was uniformly slower than it was in the same lungs when supine. In six instances, the average interval during which molecules of $\mathrm{N}_{2}$ remained was one minute in the supine position, whereas this was increased in the superior position to mean values of 1.7 and 2.7 minutes for the right and left lungs, respectively. In four instances in which clearance curves could not be analyzed, reduction of the endtidal concentration of $\mathrm{N}_{2}$ to 5 per cent required two to three minutes in the supine position and five to 11 minutes in the superior position. In four of five subjects, the clearance rate of the superior lung was slower for the left lung than for the right. These retarded clearance rates were largely the result of reduction of effective tidal volume of the superior lung, which was particularly pronounced for the left lung. Fractional replacement per breath was reduced for both the rapid and slow components.

Consistent variations with changes in position were not observed in the fractional volume of the slowly ventilated component or in the magnitude of nonuniform ventilation within an individual lung, as shown by values for delay in pulmonary clearance.

\section{DISCUSSION}

The finding that complete $\mathrm{N}_{2}$ clearance from the total lungs is slower in the lateral decubitus than in the supine position and is produced largely by a reduced clearance rate of the more slowly ventilated fraction agrees with the results of Lundin (5) and Svanberg $(6,10)$. However, Blair and Hickam (7), using helium clearance curves, did not observe such a difference in the most slowly ventilated space and did not find that ventilation was less uniform in the lateral position.

The different methods used are probably responsible for these varying results. The limited analytic range for helium permitted measurement of only the terminal 6 per cent of the total clearance curve, probably making it difficult to detect differences that become apparent when the total clearance curves can be described, as in Figure 1.

The clearance curves recorded from individual lungs by bronchospirometry were largely similar to those of Svanberg (10), except that in the present bronchospirometric studies the clearance times were longer than those of Svanberg's subjects and of our subjects studied without bronchospirometry. This retardation was apparently the result of reduced minute volumes attributable to medication. Our subjects undergoing bronchospirometry received not only morphine, as did Svanberg's, but also 1.5 grains of secobarbital (Seconal ${ }^{\circledR}$ ) and at times were nearly asleep.

Svanberg observed, as we did in this study, that functional residual capacities were larger with bronchospirometry than without, and he suggested that the resistance to flow imposed by the catheters was responsible (10). However, a pause between the end of expiratory flow and the start of inspiration, as estimated from the $\mathrm{N}_{2}$ recordings (Figure 2), was commonly seen. This would indicate that elastic rather than resistive forces were determining the end-expiratory volume. The larger functional residual capacities observed during bronchospirometry may be the result of the multiple systemic and tracheobronchial medicaments used. Our data, and those of Svanberg (10), show that the average ratio of total tidal volume to total functional residual capacity was several per cent smaller with bronchospirometry than it was without. Thus, the fractional alveolar replacement per breath normally may be slightly greater than that occurring during bronchospirometry. The absolute values of the dead space of individual lungs also must be taken with some reservation, in view of possible alterations by the drugs employed.

The bronchospirometric results indicate that at least four different alveolar clearance rates may exist throughout the lungs, particularly in the lateral positions. This was thought previously to be probable $(12,19)$. Our inability to resolve more than two or three components in $\mathrm{N}_{2}$ clearance curves of total expired gases is caused largely by limitations in defining the terminal parts of the curve, where the slowest components must be separated but where analytic accuracy for $\mathrm{N}_{2}$ has been limited and where errors in the estimated correction for blood $\mathrm{N}_{2}$ may have a relatively large effect. The terminal curve probably can be defined better with helium analyses, and results of such studies (7) suggest that fractional replacement rates even smaller than 3 to 4 per cent per 
breath, noted in the superior lungs in this study, may exist normally.

Other current problems in the analysis of $\mathrm{N}_{2}$ clearance curves may be noted. When the method of Fowler and associates (12) was modified by Lundin, Svanberg, Bouhuys and Hagstam (5, 10, 11), several apparently unrecognized consequences were introduced. The modification was that of measuring end-tidal concentration rather than the mean expired concentration as used originally (12). The use of the latter, which is a more difficult measurement, was proposed because the expired alveolar concentration may vary within the course of a single expiration, particularly with pulmonary disease, whereas only one value exists for mean expired concentration. The modification was justified by Lundin and co-workers for use in normal subjects by the experimental finding of similar values of dilution factors and fractional volumes obtained from either end-tidal values or the equivalent of mean expired concentrations. We also have found that this is generally true for normal subjects. However, by using the definitions and assumptions of the original theoretic treatment (12), one can derive several differences. In a uniformly ventilated system, either the mean expired concentration or the alveolar concentration may be used with identical results. However, in an unevenly ventilated system, the original method yields the end-expiratory fractional volumes having particular dilution factors, whereas the use of alveolar concentrations and the modified algebraic treatment (5) yields the end-inspiratory fractions, provided that the alveolar concentration selected equals the mean expired alveolar concentration. If it does not, the derived end-inspiratory fraction will be incorrect. By definition, the end-expiratory fractional volume of a relatively underventilated component is greater than its end-inspiratory fraction. Further values derived from fractional volumes and dilution factors also differ. The use of end-inspiratory fractions in the original equations (12) yields smaller values for $a$ ) the average number of breaths during which molecules of $\mathrm{N}_{2}$ remain in the system and $b$ ) the number of breaths during which molecules of $\mathrm{N}_{2}$ would have remained if ventilation had been uniform. The calculated value for delay in pulmonary clearance is also altered.
Although uneven alveolar ventilation has been known to exist for a long time, its nature (alveolar stratification vs. regional variations) and anatomic location are becoming apparent only currently. The difference in clearance rates between lungs in the lateral positions represents a regional type of uneven ventilation, and it results at least in part from differing percentage volume changes of the two lungs. Uneven ventilation within single lungs also is present. It has been found that $\mathrm{N}_{2}$ clearance is more rapid in the right lower lobe than in the right upper lobe of healthy persons in the erect position (20), and evidence of uneven intralobar ventilation has been found in man (20) and dogs (8). The variations between lungs with change in position show that relatively retarded alveolar ventilation is not restricted to a particular anatomic location. The responsible thoracic mechanics requires further study, although the ventilatory implications of the anatomy of the lungs and bronchi are becoming more evident $(21,22)$.

\section{SUM MARY}

Healthy subjects breathing oxygen had a slower rate of clearance of pulmonary nitrogen in the lateral decubitus position than when they were supine. Analysis of clearance curves showed this retardation to be the result of two factors. First, the total functional residual capacity was increased without an accompanying increase of total effective minute volume. Secondly, the proportion of the total effective minute volume that was distributed to the underventilated fraction (about 85 per cent) of the functional residual capacity was further reduced in the lateral positions.

A partial anatomic localization of the variously ventilated regions was attempted by measuring nitrogen clearance rates and the dead space of individual lungs of five normal men in the supine and both lateral decubitus positions by use of bronchospirometric catheters. Clearance curves of multiple exponential form were found, as Svanberg has noted, indicating the presence of uneven ventilation within individual lungs in all positions.

In the supine position, the tidal volume, dead space and functional residual capacity were greater for the right lung than for the left, but the clearance rates and relative magnitude of slowly and 
rapidly ventilated regions of both lungs were similar.

In lateral decubitus positions, the ventilatory pattern of the dependent lung was similar to that of the same lung in the supine position. The superior lung had an increased functional residual capacity and a decreased tidal volume. The clearance rates of both rapidly and slowly ventilated components of a lung were only half as great when it was in the superior position as they were in the same lung when the subject was supine.

The slow clearance rates of the superior lung appear to be largely responsible for the retardation of nitrogen clearance from the total lungs observed in lateral decubitus positions. This represents a regional type of uneven alveolar ventilation. The variations between lungs with change in position show that relatively retarded alveolar ventilation is not always restricted to a particular anatomic location.

\section{ACKNOWLEDGMENT}

The authors gratefully acknowledge the assistance of Rita Schmelzer, Henrietta Cranston, Bernita Rupkalvis, Jean Frank, Ruth Knutson and William Sutterer.

\section{REFERENCES}

1. Lillington, G. A., Fowler, W. S., Miller, R. D., and Helmholz, H. F., Jr. Nitrogen clearance rates of right and left lungs in different postures. Clin. Res. Proc. 1956, 4, 256.

2. Fowler, W. S. Intrapulmonary distribution of inspired gas. Physiol. Rev. 1952, 32, suppl. 1, 1.

3. Roos, A., Dahlstrom, H., and Murphy, J. P. Distribution of inspired air in the lungs. J. appl. Physiol. $1955,7,645$.

4. Forster, R. E. Exchange of gases between alveolar air and pulmonary capillary blood: Pulmonary diffusing capacity. Physiol. Rev. 1957, 37, 391.

5. Lundin, G. Alveolar ventilation (in normal subjects) analyzed breath by breath as nitrogen elimination during oxygen breathing. Scand. J. clin. Lab. Invest. 1955, 7, suppl. 20, 39.

6. Svanberg, L. Influence of posture on the volume, ventilation and circulation of the lungs. Bronches 1955, 5, 470.

7. Blair, E., and Hickam, J. B. The effect of change in body position on lung volume and intrapulmonary gas mixing in normal subjects. J. clin. Invest. 1955, 34, 383.

8. Fowler, W. S. Alveolar ventilation of individual pulmonary lobes in various postures. Amer. J. Physiol. 1951, 167, 784.
9. Miller, R. D., Fowler, W. S., and Helmholz, H. F., Jr. Changes of relative volume and ventilation of the two lungs with change to the lateral decubitus position. J. Lab. clin. Med. 1956, 47, 297.

10. Svanberg, L. Influence of posture on the lung volumes, ventilation and circulation in normals: A spirometric-bronchospirometric investigation. Scand. J. clin. Lab. Invest. 1957, 9, suppl. 25, 1.

11. Bouhuys, A., Hagstam, K.-E., and Lundin, G. Efficiency of pulmonary ventilation during rest and light exercise: A study of alveolar nitrogen washout curves in normal subjects. Acta physiol. scand. 1956, 36, 289.

12. Fowler, W. S., Cornish, E. R., Jr., and Kety, S. S. Lung function studies. VIII. Analysis of alveolar ventilation by pulmonary $\mathrm{N}_{2}$ clearance curves. J. clin. Invest. 1952, 31, 40.

13. Wright, G. W., and Michelson, E. Bronchospirometry in Methods in Medical Research, J. H. Comroe, Jr., Ed. Chicago, The Yearbook Publishers, Inc., 1950, vol. 2, pp. 82-93.

14. Lilly, J. C. Flow meter for recording respiratory flow of human subjects in Methods in Medical Research, J. H. Comroe, Jr., Ed. Chicago, The Yearbook Publishers, Inc., 1950, vol. 2, pp. 113122.

15. Cournand, A., Yarmush, I. G., and Riley, R. L. Influence of body size on gaseous nitrogen elimination during high oxygen breathing. Proc. Soc. exp. Biol. (N. Y.) 1941, 48, 280.

16. Darling, R. C., Cournand, A., and Richards, D. W., Jr. Studies on the intrapulmonary mixtures of gases. III. An open circuit method for measuring residual air. J. clin. Invest. 1940, 19, 609.

17. Fowler, W. S. Lung function studies. II. The respiratory dead space. Amer. J. Physiol. 1948, 154, 405.

18. Dahlstrom, H., Murphy, J. P., and Roos, A. Cardiogenic oscillations in composition of expired gas: The 'pneumocardingram.' J. appl. Physiol. 1954, 7,335 .

19. Bates, D. V., Fowler, W. S., Forster, R. E., and Van Lingen, B. Uniformity of alveolar ventilation at different lung volumes. J. appl. Physiol. 1954, 6, 598.

20. Martin, C. J., and Young, A. C. Lobar ventilation in man. Amer. Rev. Tuberc. 1956, 73, 330.

21. Otis, A. B., McKerrow, C. B., Bartlett, R. A., Mead, J., McIlroy, M. B., Selverstone, N. J., and Radford, E. P., Jr. Mechanical factors in distribution of pulmonary ventilation. J. appl. Physiol. 1956. 8, 427.

22. Ross, B. B. Influence of bronchial tree structure on ventilation in the dog's lung as inferred from measurements of a plastic cast. J. appl. Physiol. $1957,10,1$. 